\title{
Comparative analysis of some Bangladeshi detergents
}

\author{
M. S. Hossain*, M. S. Rana, A. Sarker and T. Khandaker \\ Chemistry Discipline, Khulna University, Khulna-9208, Bangladesh \\ Laundry detergents are widely used in domestic, industry and other sectors everyday all over the world. It consists of different \\ chemical components; surfactants, phosphate, builders, bleaches, optical brighteners, anti-redepositing agents, enzyme, perfume and \\ color. Among these ingredients, surfactants and phosphate are considered as hazardous materials. With this view, composition, critical \\ micelle concentration, and dissolved oxygen (DO) level in aqueous solution of some laundry detergents available in Bangladesh such \\ as Chaka, Keya, Rin, Jet and Smart were determined and try to analyzed the chemical contribution of laundry detergents to pollute \\ the environment. For Smart and Rin, the surfactant and phosphate amount were maximum, while it was minimum in Chaka and Jet \\ respectively. The DO level was minimum in Smart and maximum in Jet. The results indicated that Jet is the effective laundry detergent \\ in both cleaning and environmental aspect.
}

Keywords: Surfactant; Phosphate; Dissolved Oxygen (DO); Environmental effect

\section{Introduction}

In our daily life, we use the detergents as a cleaning compound for diverse purposes. Surfactants, builders, and bleaches are the main ingredients in laundry detergents (Schramm et al., 2003). The major constituent of detergents is Surfactant; it has the characteristics of high biological activity and tendency to accumulate in organisms, making adverse effects. It plays three important roles-wetting the fabrics, loosening dirt from fabrics, and emulsifying and keeping dirt suspended in the wash solution. The annual global production of surfactants was 13, 000.0 KT in 2008 (Levison, 2009).

Builders are key detergent components which remove the calcium and magnesium ions presents in hard water and in soils, thus lowering the concentration of surfactants necessary to perform the detersive action. Some builders also prevent the deposition of calcium and magnesium salts on fabrics and washing machines. The most commonly used builder, sodium tripolyphosphate, leads to the eutrophication effect (Jagessar and Sooknanan 2011).

Laundry detergent play a special characteristic that it is less affected by hard water than Soap, though the chemical compound is similar. The critical micelle concentration (CMC) values are important in virtually all of the process industry surfactant applications, from mineral processing to formulation of personal care products and foods, to drug delivery systems, and to new surfactant remediation technologies. It always varies for the physico-chemical properties of surfactants (Mittal and Lindman, 1984). For the characteristics of interfacial tension lowering, emulsification, suspension stabilization, in promoting foam stability, the concentration achieved higher than the $\mathrm{CMC}$ in the presence of significant concentration of micelles (Schramm, 1992, 1994). The foaming stability directly related with the cleansing efficiency of laundry detergents (Shinoda et al., 1963). So, micellar studies are interested for laundry detergents. The $\mathrm{CMC}_{\mathrm{s}}$ were determined by the conductivity measurements and the surfactants and phosphate by UV-vis spectroscopic method. The DO level in laundry detergents were determined by the Winkler iodometric titration method (Winkler, 1888). From the experimental results, the comparative discussion was made on the cleansing efficiencies and identification of less harmful laundry detergent for environment.

\section{Methods and materials}

Sodium dodecyl sulfate (SDS) (purity, $99 \%$ ), $\mathrm{NaOH}$ (purity, $98 \%$ ), $\mathrm{Na}_{2} \mathrm{CO}_{3}$ (purity, $99 \%$ ), methylene chloride (purity, $99.9 \%$ ), $\mathrm{MnSO}_{4}$ (purity, $99 \%$ ), $\mathrm{H}_{2} \mathrm{SO}_{4}$ (purity, $98 \%$ ), $\mathrm{KH}_{2} \mathrm{PO}_{4}$ (purity, $99.5 \%$ ), $\mathrm{HCl}$ (purity, $37 \%$ ), $\mathrm{K}_{2} \mathrm{Cr}_{2} \mathrm{O}_{7}$ (purity, $99.9 \%$ ), potassium iodide (KI) (purity, $99 \%$ ), $\mathrm{Na}_{2} \mathrm{~S}_{2} \mathrm{O}_{3}$ (purity, $98 \%$ ), Methylene blue (purity, $98.9 \%$ ) and ammonium molybdate (purity, $98.9 \%$ ) were procured for Loba Chemie Private Limited, India. All the chemicals were used without further purification. Redistilled and deionized water was used for solution preparation by dilution method.

Nowadays, many of the cleaning of the cleaning detergents are available in the market. The composition and effect of DO were analysed from the selected laundry detergents such

\footnotetext{
*Corresponding author e-mail: hsarwar86@yahoo.com
} 
as Chaka, Keya, Rin, Jet and Smart. The selected sample were purchased and stored in dry conditions over the entire period of research. The name of the manufacturers and ingredients labeled on the packages of laundry detergents selected for this study is shown below: following equation:

$$
\text { Content of surfactant }(0 \% w / w)=\frac{(y-c)}{m X} \times 100
$$

where $y$ is the absorbance of laundry detergent solutions of concentration, $X(\% \mathrm{w} / \mathrm{v})$

\begin{tabular}{lll}
\hline Brand & Ingredients name (declared by manufacturer) & Company Name \\
\hline Chaka & Soda ash light, $\mathrm{Na}_{2} \mathrm{SO}_{4}$, Linear alkyl benzene sulfonic acid (LABSA), Aqua, Perfume. & Square Toiletries Ltd. \\
\hline Keya & Linear alkyl benzene sulfonate (LAS), $\mathrm{CaCO}_{3}, \mathrm{Na}_{2} \mathrm{CO}_{3}$, perfume, color. & Keya Cosmetics Ltd. \\
\hline Rin & Sodium Linear alkyl benzene sulfonate(LAS), $\mathrm{Na}_{2} \mathrm{CO}_{3}$, Hueing agent, Optical Brighteners, Perfume. & Uniliver Bangladesh Ltd. \\
\hline Jet & $\begin{array}{l}\text { Florescent brightener, Linear alkyl benzene sulfonate A. D (LAS AD), Sulfate, Soda Ash, Perfume, . . } \\
\text { Zeolite, Per-borate }\end{array}$ & Kallol Group of Company \\
\hline Smart & Soda ash, Linear alkyl benzene sulfonic acid (LABSA), $\mathrm{CaCO}_{3}$, Dolomite, Perfume. & ACI Limited \\
\hline
\end{tabular}

In present work, the content of surfactant in Keya, Rin, Chaka, Smart and Jet were determined at room temperature by MBAS colorimetric method employing UV-Vis spectrophotometer (Ibanez et al., 2008; Sar et al., 2009) where methylene chloride used as solvent and methylene blue used as organic dye. The absorbance was measured by spectrophotometer at $654 \mathrm{~nm}$. It made sure that the spectrophotometer was previously calibrated using the methylene chloride so as to adjust the transmittance to $100 \%$.

The content of phosphates in selected laundry detergents were determined at room temperature by colorimetric method employing UV-Vis spectrophotometer (Ibanez et al., 2008), where stannous chloride, $\mathrm{SnCl}_{2}$ was used as a reducing agent. The absorbance was measured by spectrophotometer at a wavelength of $690 \mathrm{~nm}$ and it was adjusted to $100 \%$ transmittance with deionised water.

Although surfactants and builders' ingredients of laundry detergents play vital role for cleansing action, their extensive usages cause great risk for water environment, such as decreasing DO level, eutrophication effect (Ibanez et al., 2007) and so on. The effect of selected laundry detergents available in Bangladesh on DO level were determined by Winkler method (Winkler, 1888).

\section{Results and discussion}

\section{Surfactant and phosphate contents}

The absorbance of the standard SDS and $\mathrm{KH}_{2} \mathrm{PO}_{4}$ aqueous solutions of different concentrations is shown in Table I. (values of $m, c$, and other regression statistics are also included). The absorbance of laundry detergent solutions at different concentrations is represented in Table II. The contents of surfactants/phosphates in laundry detergents were calculated from measured absorbance using the
The average contents of surfactant and phosphate in selected laundry detergents were listed in Table II and Fig. 1 from which it was apparent that the contents of surfactant in laundry detergents followed the order: Smart $>$ Rin $>$ Keya $>$ Chaka > Jet. The amount of surfactant in Smart and Rin is higher and Jet and Chaka is lower. In this case, the usage of Smart laundry detergent is a great risk for water environment than others.

The average contents of phosphate in selected laundry detergents were listed in Table II and Fig.1 from which it followed the order: Rin $>$ Smart $>$ Keya $>$ Chaka $>$ Jet. From this trend, Jet and Chaka contained minimum amount of phosphate while that for Rin and Smart was maximum. So, Jet is the efficient cleansing laundry detergent for water environment than other studied detergents.

\section{DO level in aqueous detergent solutions}

The eroded volume of standard sodium thiosulfate solutions for the titration of liberated molecular iodine was used to calculate the DO level in detergent solutions using the following relationship:

$$
\text { DO level }(p p m)=\frac{M \times C \times V_{1}}{4 \times V_{2}}
$$

where $\mathrm{M} /\left(\mathrm{mg} \mathrm{mol}^{-1}\right)$ is the molar mass of $\mathrm{O}_{2}$ and $\mathrm{C} /\left(\mathrm{mol} \mathrm{L}^{-1}\right)$ and $V_{I} / m L$ are the concentration and volume of $\mathrm{Na}_{2} \mathrm{~S}_{2} \mathrm{O}_{3}$, respectively; $V_{2} / m L$ is the volume of detergent solutions or air-saturated pure water. The standard DO level in freshwater at $298.15 \mathrm{~K}$ is $8.2628 \mathrm{ppm}$ reported by Benson and Krause (1980).

The measured DO levels are listed in Table III and Fig. 2 which demonstrates that the maximum DO level is in Jet. It is concluded that the usage of Jet for cleaning purpose is better for aquatic beings than other studied detergents. 
Table I. Experimental absorbance of SDS and $\mathrm{KH}_{2} \mathrm{PO}_{4}$ aqueous solutions and fitting parameters

\begin{tabular}{|c|c|c|c|c|c|}
\hline Standard & Concentration & Absorbance & Intercept, $c$ & Slope, $m$ & $R^{2}$ \\
\hline SDS & $\begin{array}{l}0.0000 \\
0.0001 \\
0.0010 \\
0.0020 \\
0.0030 \\
0.0040 \\
0.0050\end{array}$ & $\begin{array}{l}0.152 \\
0.195 \\
0.337 \\
0.528 \\
0.915 \\
1.293 \\
1.631\end{array}$ & $0.1718( \pm 0.016)$ & $358.62( \pm 5.80)$ & 0.9982 \\
\hline $\begin{array}{l}\text { Phosphate } \\
\text { Solution }\end{array}$ & $\begin{array}{l}0.0000 \\
0.0001 \\
0.0002 \\
0.0003 \\
0.0004 \\
0.0005 \\
0.0006 \\
0.0007 \\
0.0008 \\
0.0009 \\
0.0010 \\
\end{array}$ & $\begin{array}{l}0.000 \\
0.020 \\
0.052 \\
0.066 \\
0.095 \\
0.113 \\
0.143 \\
0.157 \\
0.181 \\
0.196 \\
0.223 \\
\end{array}$ & $0.0037( \pm 0.0031)$ & $219.76( \pm 4.99)$ & 0.9954 \\
\hline
\end{tabular}

Table II. Absorbance, contents of surfactants and phosphate in laundry detergents

\begin{tabular}{|c|c|c|c|c|c|c|c|c|}
\hline \multirow{2}{*}{$\begin{array}{c}\text { Name of } \\
\text { Laundry } \\
\text { detergents }\end{array}$} & \multicolumn{4}{|c|}{ Surfactant content } & \multicolumn{4}{|c|}{ Phosphate content } \\
\hline & $\begin{array}{l}\text { Concentration } \\
\text { of detergent, } \\
\mathrm{X} /(\% \mathrm{w} / \mathrm{v})\end{array}$ & Absorbance & $\begin{array}{l}\text { Surfactant } \\
\text { content/ } \\
(\% \mathrm{w} / \mathrm{w})\end{array}$ & $\begin{array}{l}\text { Average of } \\
\text { Surfactant } \\
\text { content } / \\
(\% \mathrm{w} / \mathrm{w})\end{array}$ & $\begin{array}{c}\text { Concentration } \\
\text { of detergent, } \\
\mathrm{X} / \\
(\% \mathrm{w} / \mathrm{v})\end{array}$ & Absorbance & $\begin{array}{l}\text { Phosphate } \\
\text { content/ } \\
(\% \mathrm{w} / \mathrm{w})\end{array}$ & $\begin{array}{l}\text { Average of } \\
\text { Phosphate } \\
\text { content/ } \\
(\% \mathrm{w} / \mathrm{w})\end{array}$ \\
\hline \multirow{3}{*}{ Chaka } & 0.005 & 0.290 & 6.590 & \multirow{3}{*}{$6.84( \pm 0.22)$} & 0.0036 & 0.0580 & 6.864 & \multirow{3}{*}{$7.190( \pm 0.19)$} \\
\hline & 0.010 & 0.433 & 7.282 & & 0.0065 & 0.1110 & 7.512 & \\
\hline & 0.015 & 0.529 & 6.640 & & 0.0102 & 0.1650 & 7.196 & \\
\hline \multirow{3}{*}{ Keya } & 0.005 & 0.299 & 7.092 & \multirow{3}{*}{$7.36( \pm 0.29)$} & 0.0045 & 0.0770 & 7.412 & \multirow{3}{*}{$7.438( \pm 0.02$} \\
\hline & 0.010 & 0.457 & 7.952 & & 0.0064 & 0.1090 & 7.487 & \\
\hline & 0.015 & 0.551 & 7.049 & & 0.0095 & 0.1585 & 7.415 & \\
\hline \multirow{3}{*}{ Jet } & 0.005 & 0.347 & 9.769 & \multirow{3}{*}{$9.35( \pm 0.25)$} & 0.0041 & 0.0850 & 9.023 & \multirow{3}{*}{$8.606( \pm 0.21)$} \\
\hline & 0.010 & 0.491 & 8.900 & & 0.0074 & 0.1410 & 8.443 & \\
\hline & 0.015 & 0.677 & 9.391 & & 0.0110 & 0.2056 & 8.352 & \\
\hline \multirow{3}{*}{ Rin } & 0.005 & 0.417 & 13.672 & \multirow{3}{*}{$13.70( \pm 0.07)$} & 0.0033 & 0.1060 & 14.106 & \multirow{3}{*}{$13.845( \pm 0.20)$} \\
\hline & 0.010 & 0.668 & 13.835 & & 0.0061 & 0.1910 & 13.972 & \\
\hline & 0.015 & 0.903 & 13.592 & & 0.0098 & 0.2935 & 13.456 & \\
\hline \multirow{3}{*}{ Smart } & 0.005 & 0.521 & 19.472 & \multirow{3}{*}{$18.08( \pm 0.71)$} & 0.0027 & 0.0810 & 13.028 & \multirow{3}{*}{$12.649( \pm 0.23)$} \\
\hline & 0.010 & 0.786 & 17.126 & & 0.0055 & 0.1570 & 12.683 & \\
\hline & 0.015 & 1.121 & 17.645 & & 0.0089 & 0.2430 & 12.235 & \\
\hline
\end{tabular}




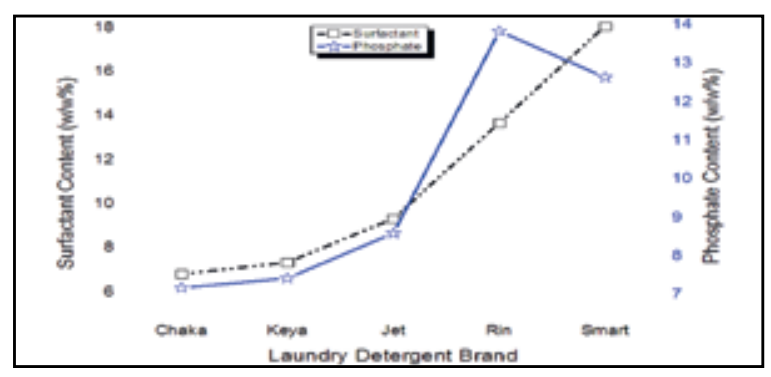

Fig. 1. Relative representation of required amount of laundry detergents for discharged amount of surfactant (square) and phosphate (star)

Table III. The dissolved oxygen (DO) level in the freshwater and detergent solutions at $25{ }^{\circ} \mathrm{C}$

\begin{tabular}{lcc}
\hline Brands & $\begin{array}{c}\text { Concentration of detergent/ } \\
(\mathrm{ppm})\end{array}$ & $\begin{array}{c}\text { DO level/ } \\
(\mathrm{ppm})\end{array}$ \\
\hline Water & 0.0000 & 8.32 \\
Jet & 0.7466 & 5.45 \\
Chaka & 0.3379 & 5.31 \\
Keya & 0.3488 & 5.19 \\
Rin & 0.3846 & 5.06 \\
Smart & 0.6104 & 4.91 \\
\hline
\end{tabular}

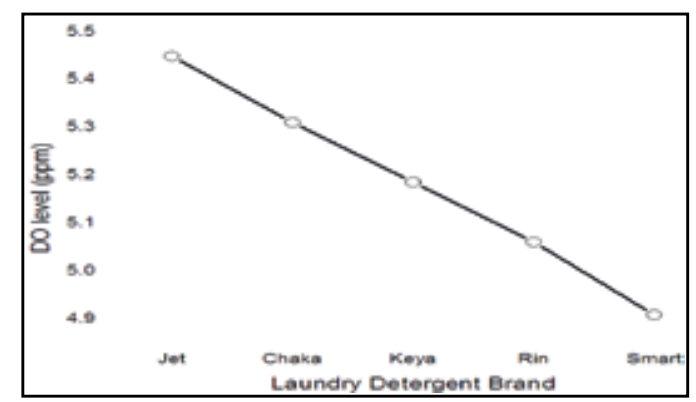

Fig. 2. Relative representation of required amount of laundry detergents for dissolved oxygen level

\section{Conclusion}

The study on laundry detergents finally concluded that, it has great importance with respect to environmental aspects. Smart is relatively efficient cleaner than others, because it contains medium amount of phosphate and maximum amount of surfactant which are the cleaning agent; and contain minimum amount of DO level, which implies that it is not suitable detergent with respect to environmental aspects. On the other hand, Jet contains moderate amount of surfactant and phosphate and has maximum DO level. So, Jet is the best laundry detergent in both cleaning and environmental (less harmful for environment) aspect.

\section{Acknowledgement}

The authors are grateful to the Chemistry Discipline, Khulna
University, Bangladesh, for providing financial support and laboratory facilities to carry out this research work.

\section{References}

Benson BB and Krause D (1980) The concentration and isotopic fractionation of gases dissolved in freshwater in equilibrium with the atmosphere Oxygen, Limnol Oceanogr 25: 662-671.

Ibanez JG, Esparza MH and Doria-Serrano C (2007), Environmental chemistry: microscale laboratory experiments $\mathbf{1 0 5}$.

Ibanez JG, Esparza MH and Doria-Serrano C (2008), Environmental chemistry: microscale laboratory experiments, Springer Science and Business Media, LLC, New York.

Jagessar RC, Sooknanan L (2011), Spectrophotometric determination of phosphates $\left(\mathrm{PO}_{4}^{3-}\right)$ anion in waste water from selected areas of Coastal Guyana via the stannous chloridemolybdate calorimetric method, Int $J$ Acad Res 3: 98-107.

Levison MI (2009), Surfactant production: present realities and future perspectives In: Handbook of detergents, Part F, Vol. 2, CRC, Boca Raton, pp 1-38.

Mittal KL and Lindman B (1984), Surfactants in Solution, Ed. Plenum, Vol. 1-3, New York.

Sar SK, Verma C, Pandey PK, Bhui A (2009), Reliable technique for the determination of sodium dodecyl sulphate by crystal violet in relation to the effluents of Durg-Bhilai region, J Chin Chem Soc 56: 1250-1256.

Schramm LL (1992), Emulsions, Fundamentals and Applications in the Petroleum Industry, Ed. American Chemical Society, Washington DC.

Schramm LL (1994), Foams, Fundamentals and Applications in the Petroleum Industry, Ed. American Chemical Society, Washington DC.

Schramm LL, Stadium EN and Marangoni DG (2003), Surfactants and their applications, Annu. Rep. Prog. Chem. 99: 5 .

Shinoda K, Nakagawa T, Tamamushi BI and Isemura T (1963), Colloidal Surfactants: Some Physicochemical Properties, Academic Press, New York.

Winkler LW (1888), Die bestimmung des imwasser gelöstensauerstoffes, Berichte der Dtsch Chem Gesellschaft 21: 2843-2854.

Received: 13 February 2017; Revised: 27 February 2017; Accepted: 29 May 2017. 